\title{
Strutural Interpretation of High Resolution Aeromagnetic Data in Takutu Rift, Brazil
}

Passos, Marcel. S., Vidotti, Roberta. M., Programa de Pós-graduação em Geologia, Instituto de Geociências, Universidade de Brasilia

Copyright 2021, SBGf - Sociedade Brasileira de Geofísica.

This paper was prepared for presentation during the $17^{\text {th }}$ International Congress of the Brazilian Geophysical Society held in Rio de Janeiro, Brazil, $16-19$ August 2021.

Contents of this paper were reviewed by the Technical Committee of the $17^{\text {th }}$ International Congress of the Brazilian Geophysical Society and do not necessarily represent any position of the SBGf, its officers or members. Electronic reproduction or storage of any part of this paper for commercial purposes without the written consent of the Brazilian Geophysical Society is prohibited.

\begin{abstract}
Located in the central-eastern portion of the state of Roraima, extending to the western region of Guyana, occurs the Takutu Rifte, a NE-SW-trending distensive structure with dimensions of $300 \mathrm{~km}$ in length and 30 to $50 \mathrm{~km}$ in width, it was generated by the reactivation of pre-existing structures, having its genesis associated with the separation of the South American and African plates, during the fragmentation of Pangea. This rift still does not have a well-defined structural framework, due to scarce studies that focused on its first oil exploration campaigns, carried out by Petrobras in the 1980s, through seismic surveys and the drilling of two dry wells in its Brazilian portion. In Guyana, where it was also explored, through pioneering studies carried out by Hunt Oil, finding subcommercial oil in fractured basalt, confirming the basin's potential for hydrocarbons, despite the nonconventional reservoirs finds. A large part of the anticlines in the Guyanas region were subjected to a tertiary hydrothermal event, which led to the overmaturation of the source rocks and destroyed a large part of the porosity of the reservoir rocks. The processing of new high resolution magnetic data, from the Aerogeophysical Project Center-East of Roraima, showed in greater detail the internal structures of the rift, which allowed the interpretation of magnetic domains, which were named based on lithologies of the region and nomenclatures of past studies, defining the structural provinces Boa Vista, Bonfim and Serra do Tucano. These present distinct textural and structural aspects, highlighted by changes in the directions of the magnetic lineaments, in addition to distinct depths in each of the provinces, individualized by means of the Matched Filter (330, 790 and 9,440 m) and Euler Deconvolution (from 100 to $8,000 \mathrm{~m}$ ). In addition, it is important to emphasize that the boundaries between these structural provinces are marked by regional fault, named Fault of Takutu and Fault of Mel, in reference to the drainages that occur in these regions. These interpretations shows post-rift deformations, associated with a transcurrent event of tertiary age, in which sinister kinematics are observed, marked by curved to wavy magnetic lineaments and sigmoidal structures, which are also pointed out in field data by other authors.
\end{abstract}

